\title{
Morretes: um estudo sobre a governança entre cidade e ferrovia'
}

\section{Morretes: a study on city-rail governance}

\author{
D'Agostini, Fernanda F.1; Abascal, Eunice H.S.²
}

\author{
' Universidade Anhembi Morumbi, Rua Casa do Ator, 275 - Vila Olímpia, Brasil \\ e arq.fernandafd@gmail.com \\ 2 Universidade Presbiteriana Mackenzie e eunicehab@gmail.com
}

\begin{abstract}
RESUMO
A ferrovia atravessa um território formado por municípios que podem ser encarados de maneira integrada, se adotada uma perspectiva regional de ação e planejamento; uma ferrovia turística é um potencial vetor de implementação de atividades em um território municipal e regional, razão pela qual, por seu papel de possível fator de agregação de atividades econômicas ao território, é um impulsionador de desenvolvimento local, por se vincular ao território alvo. Este artigo tem como objetivo demonstrar as consequências socioterritoriais da dependência de uma cidade de um produto turístico e, principalmente, evidenciar a distância entre as ações públicas e privadas quanto à manutenção e desenho urbano tendo como objeto de estudo a Ferrovia Curitiba - Paranaguá e a cidade de Morretes no estado do Paraná. Para tanto adota-se como método de análise e avaliação a aplicação de indicadores pré-definidos e a análise SWOT como mecanismo de racionalização e prospecção de cenários. Este estudo traz como contribuição a discussão de institucionalidades em governança urbana, em iniciativas multiagentes.
\end{abstract}

Palavras-chave: ferrovia turística, desenho urbano, governança.

\begin{abstract}
The railroad crosses a territory formed by municipalities that can be approached in an integrated way, adopting a regional perspective of action and planning; a tourist railroad is a potential vector for the implementation of activities in a municipal and regional territory, because of its role as a possible aggregation of economic activities in the territory, because it is linked to the target territory. This article aims to demonstrate the socio-territorial consequences of the dependence of a city on a tourism product and to show the distance between public and private actions regarding urban maintenance and design, with the object of study being the Ferrovia Curitiba - Paranaguá and the city of Morretes in the state of Paraná. The application of pre-defined indicators and the SWOT analysis as a mechanism for rationalizing and prospecting scenarios are adopted as a method of analysis and evaluation. This study brings as contribution the discussion of institutions in urban governance, in multiagent initiatives.
\end{abstract}

Keywords: tourist railway, urban design, governance.

\footnotetext{
${ }^{1}$ D'AGOSTINI, Fernanda F.; ABASCAL, Eunice H. S. Morretes: um estudo sobre a governança entre cidade e ferrovia. In: II SIMPÓSIO NACIONAL DE GESTÃO E ENGENHARIA URBANA: SINGEURB, 2019, São Paulo. Anais... Porto Alegre: ANTAC, 2019.
} 


\section{UMA FERROVIA E UMA CIDADE}

A Estrada de Ferro Curitiba-Paranaguá é atualmente responsável pelo escoamento de carga para o Porto Paranaguá com uma média diária de cento e noventa vagões em grande maioria de grãos provindos do Centro-sul do país, segundo a APPA - administração dos Portos de Paranaguá e Antonina e está sob concessão da RUMO Logística após fusão com a ALL América Latina Logística em 2015. Paralelamente a esse tráfego de carga acontece o transporte de passageiros turístico administrado pela Serra Verde Express após licitação realizada em 1996 e Contrato de Concessão de Prestação de Serviços de Transporte Ferroviário de Trens de Turismo n 01/ERCUB/RFFSA/97 de 27 de março de 1997 assinado entre o consórcio Pontal do Paraná Ltda.

A ferrovia está inserida na região turística do litoral paranaense conforme mapa de regionalização do turismo brasileiro e o turismo implementado baseia-se no valor cultural da cidade de Morretes, apropriando-se da configuração urbanística e arquitetônica que remontam ao século XVI e de sua culinária local onde destaca-se o Barreado que é um prato típico do litoral paranaense de influência portuguesa que ganhou esse nome devido ao seu processo de cozimento conhecido como "barrear" que consiste em panela de barro selada com uma mistura de farinha de mandioca, cinza de fogão e água e, em alguns casos, também com uma folha de bananeira.

Porém, ressalta-se que muito do sucesso desta ferrovia turística se deve a cidade de Curitiba por suas políticas públicas voltadas ao turismo como base econômica, facilitando o processo de divulgação do passeio. Entretanto, torna-se fundamental o entendimento dos processos de concessão dessa ferrovia, por se tratar de um ramal ativo, ao contrário do que acontece na maioria das ferrovias turísticas brasileiras que funcionam em ramais desativados ou mesmo devolvidos para a União, toda a operacionalização é feita pela RUMO, cabendo a Serra Verde Express apenas os direitos exclusivos de comercialização dos passeios e receptivo turístico, assim como é repassado um valor referente a alocação dos funcionários, locomotiva e instalações na estação para a RUMO.

Apenas parte da Estação Morretes está em funcionamento de forma precária, visto que o edifício demonstra um alto grau de degradação: o edifício principal apresenta uma série de patologias que evidenciam a falta de manutenção. O comprimento da plataforma - mesmo todo o conjunto da estação (edifício em uso e edifício fechado), não atendem ao comprimento total do comboio do trem turístico, ocasionando o fechamento das vias entre a estação em todo o tempo necessário para o desembarque que acontece em fases de acordo com a capacidade da plataforma em funcionamento levando em média de 45 a 50 minutos, impactando diretamente os moradores que perdem temporariamente seu direito de ir e vir pela interdição das vias (figura 01). Ressalta-se que grande parte da população reside do lado oposto à estação - depois dos trilhos, visto que estes dividem a cidade ao mesmo tempo que junto a atividade econômica do turismo segregam o tecido urbano, já que do lado da estação estão a igreja, a praça central com o edifício da prefeitura e todo o centro comercial voltado ao atendimento do turista, evidenciando a cenarização da cidade para sua promoção dentro dos conceitos discutidos do city marketing. 
Figura 01 - Impacto do trem turístico no cotidiano dos moradores

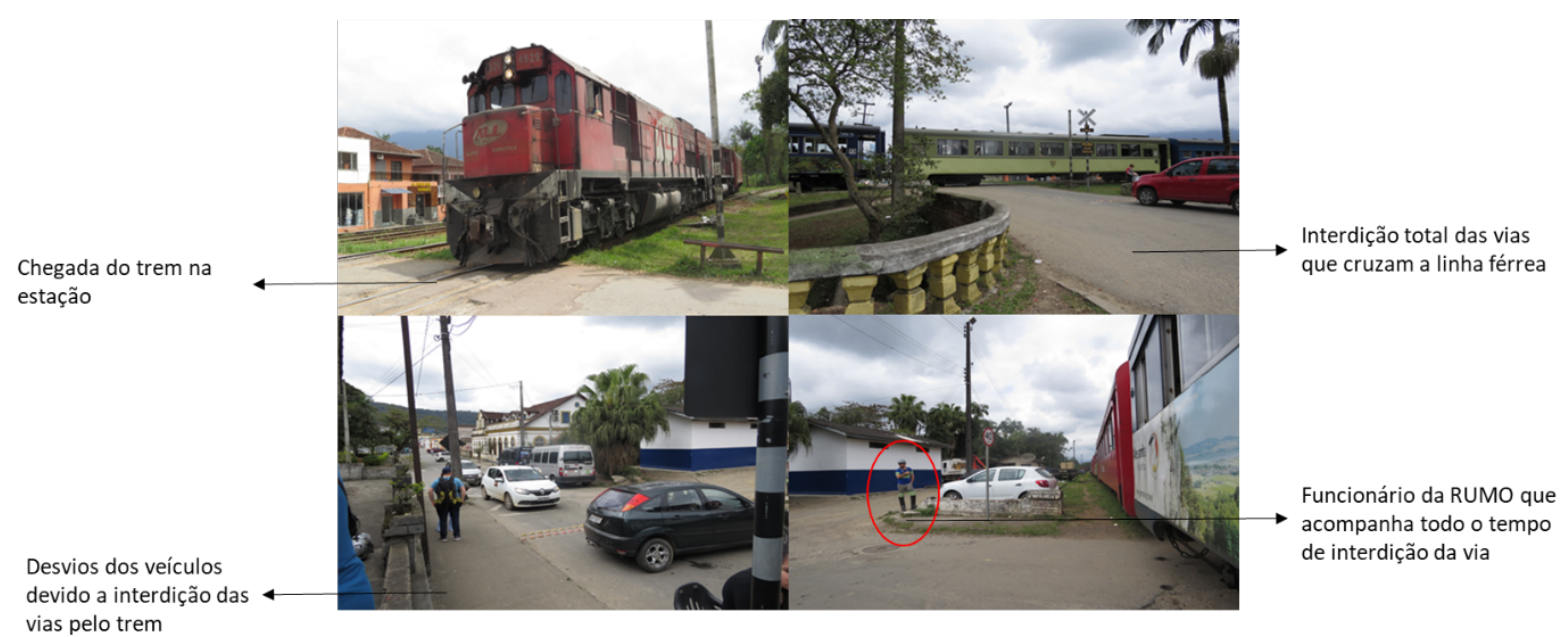

Fotos: Fernanda F. D'Agostini, set/18

A evidência do impacto social causado por esse processo de venda do território é observada claramente não só pelo desenho urbano, mas, principalmente, pela observação das construções contidas após a linha do trem que se constituem de residências térreas de alvenaria simples e outras de barracos mesclando madeira e alvenaria.

Nos primeiros vinte anos de funcionamento foi oferecido diariamente o passeio de trem, o que diferenciava essa ferrovia das demais ferrovias turísticas brasileiras, porém em 2018, a ANTT reavaliou-a e considerou o serviço prestado de natureza não regular e turística levando ao fim do Contrato $n^{\circ}$ 01/ERCUB/RFFSA/97 e a adequação do serviço às disposições da Resolução ANTT n. ${ }^{\circ}$ 359/2003, aplicável a todas as empresas que operam serviços com a mesma natureza, que dispõe sobre os procedimentos relativos à prestação não regular e eventual de serviços de transporte ferroviário de passageiros com finalidade turística, históricocultural e comemorativa (ANTT, 2018).

Essas ações levaram a Serra Verde Express e a Rumo Malha Sul S/A a firmarem um Contrato Operacional Específico (COE) que traz dentre as cláusulas exigidas aos fluxos estimados e roteiros previstos para circulação do trem. Nesse sentido tanto a forma de operação, quanto os horários e dias de circulação do trem foram pactuados entre as partes e ratificados por meio do COE (ANTT, 2018). Esse acordo culminou na mudança da oferta de viagens que deixou de ser diária para funcionamento apenas aos finais de semana e feriados, com exceção dos meses de janeiro e julho - considerados meses de férias escolares que a oferta é ampliada passando a ser de quinta a domingo.

A diminuição do fluxo de turistas provindos do trem turístico impactou a economia local, principalmente no comércio que depende quase que exclusivamente do público externo, esse fenômeno foi amplamente retratado nas mídias locais, resultando na reação, principalmente do setor privado, que buscou a inserção de novos atrativos e produtos turísticos de forma a fomentar um novo fluxo de turistas independente do trem.

O esforço do setor privado para a manutenção do turismo como base econômica não retrata a mesma força na municipalidade, visto que, a infraestrutura receptiva da cidade apresentase frágil e degradada, assim como por parte da concessionária RUMO quanto ao patrimônio construído da ferrovia, onde várias edificações, além da estação, sofrem com a falta de manutenção e preservação do patrimônio (figura 02). 
Figura 02 - Patrimônio edificado da ferrovia em estado em estado de conservação precário

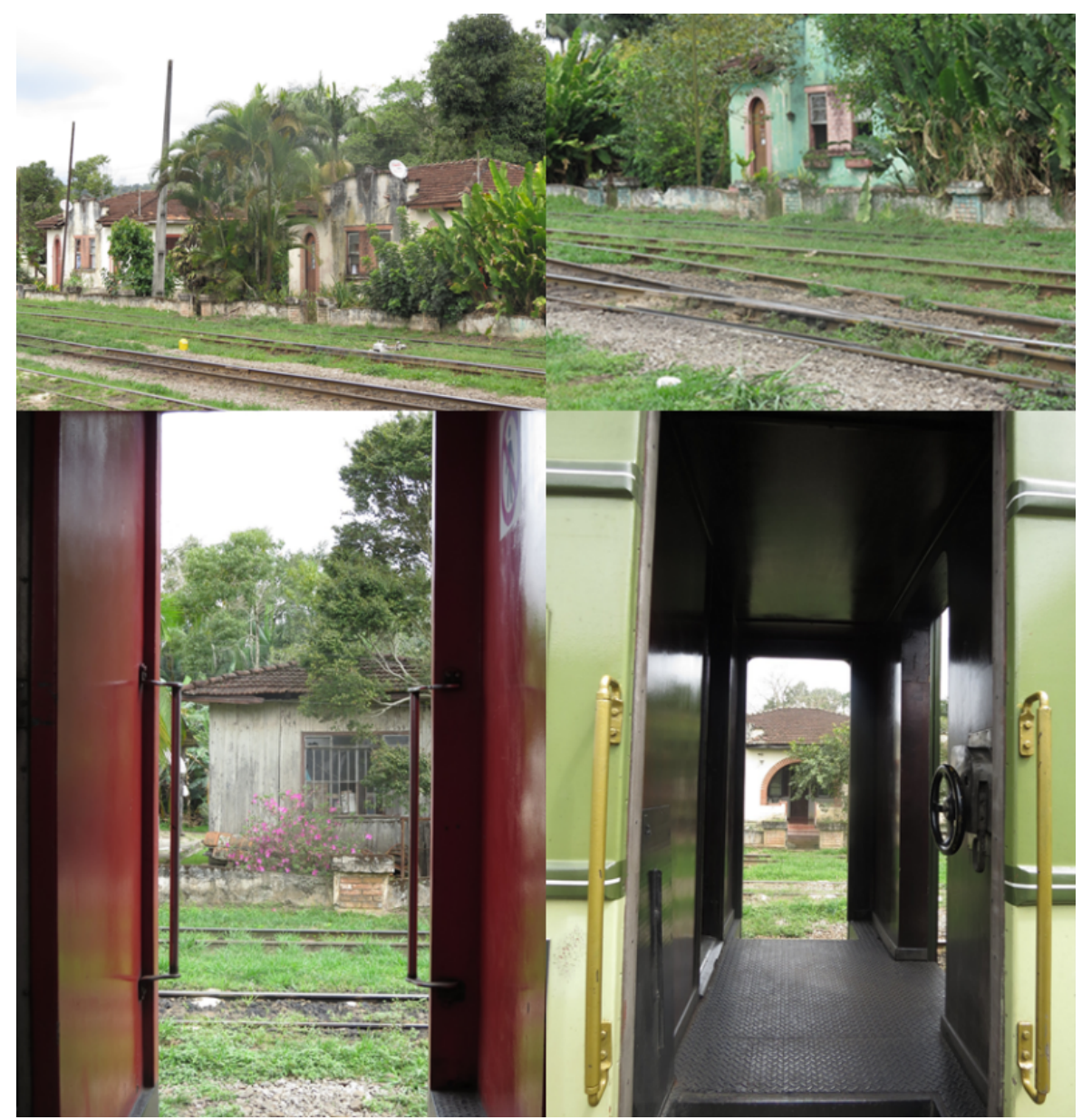

Fotos: Fernanda F. D'Agostini, set/18

\section{ANÁLISE E AVALIAÇÃo}

Neste contexto e como uma forma de fomento do produto turístico - trem e incentivo ao turismo local o estado implantou em 2018, após reestruturação dos serviços, um programa de desconto nas passagens para moradores das cidades paranaenses, principalmente curitibanos, porém este é válido apenas para as quintas e sextas feiras exceto feriados e datas comemorativas, restringindo o aproveitamento desse público ao passeio e experiência.

Para análise e avaliação da Ferrovia Turística Curitiba - Morretes, aplicam-se os indicadores formulados para este estudo e se considera o período de funcionamento da ferrovia, conforme mostra o quadro a seguir: 


\section{FERROVIA TURISIICA CURIIIBA-PARANAGUÁ-Morreles/PR}

\begin{tabular}{|c|c|c|c|}
\hline \multicolumn{4}{|c|}{ Indicador:histórico-econômico } \\
\hline Parâmełro & Critérios & Efeitos | Consequências & $\begin{array}{l}\text { Valor } \\
\text { do } \\
\text { Indica } \\
\text { dor }\end{array}$ \\
\hline \multirow[t]{2}{*}{ Desenho } & $\begin{array}{l}\text { Morfologia } \\
\text { Urbana }\end{array}$ & $\begin{array}{l}\text { Morretes apresenta uma configuração típica das cidades brasileiras } \\
\text { com sua fundação e crescimento inicial dado pela lgreja e } \\
\text { posteriormente modificada pela implantação da ferrovia, o que } \\
\text { levou a segregação do tecido urbano intensificada pela } \\
\text { cenarização da cidade para o turista. }\end{array}$ & 1 \\
\hline & $\begin{array}{l}\text { Espaços } \\
\text { Públicos }\end{array}$ & $\begin{array}{l}\text { Não há nenhum tipo de contrapartida ou mesmo de promoção de } \\
\text { espaços públicos pela ferrovia, que por sua vez utiliza-se da cidade } \\
\text { tanto pela interrupção das vias para passagem dos comboios } \\
\text { como também para a recepção dos passageiros do trem turístico. }\end{array}$ & 2 \\
\hline \multirow[t]{2}{*}{$\begin{array}{l}\text { Desenvolvi- } \\
\text { mento }\end{array}$} & $\begin{array}{c}\text { Geração de } \\
\text { empregos }\end{array}$ & $\begin{array}{l}\text { Devido ao grande fluxo de turistas na cidade provindos do trem há } \\
\text { a geração de empregos indiretos no comércio e serviços voltados } \\
\text { ao atendimento desse público. }\end{array}$ & 3 \\
\hline & Mobilidade & $\begin{array}{l}\text { Não existe nenhum tipo de transporte férreo para os moradores. Há } \\
\text { uma dificuldade de transposição das vias quando do desembarque } \\
\text { dos passageiros gerando um bloqueio e dificultando a mobilidade. }\end{array}$ & 1 \\
\hline \multirow[t]{3}{*}{ Gestão } & Infraestrutura & $\begin{array}{l}\text { A gestão pública e privada dos órgãos responsáveis pela ferrovia } \\
\text { não tem atendido a demanda existente quanto a infraestrutura } \\
\text { visto que não há espaços públicos adequados para o recebimento } \\
\text { do turista, assim como, o edificio da estação se encontra em } \\
\text { estado de degradação. }\end{array}$ & 1 \\
\hline & $\begin{array}{l}\text { Contrapartid } \\
\text { as territoriais }\end{array}$ & $\begin{array}{l}\text { Não há contrapartidas territoriais diretas, a concessionária da } \\
\text { ferrovia e a empresa de turismo não apresentam nenhum tipo de } \\
\text { plano ou projeto para melhoramento e aprimoramento dos } \\
\text { espaços públicos ou infraestrutura de atendimento a demanda } \\
\text { local. }\end{array}$ & 1 \\
\hline & & Indicadors planos e projelos urbanos e furisticos & \\
\hline \multirow[t]{5}{*}{$\begin{array}{l}\text { Pontos de } \\
\text { convergên } \\
\text { cia }\end{array}$} & $\begin{array}{l}\text { Abrangência } \\
\text { dos planose } \\
\text { projetos }\end{array}$ & $\begin{array}{l}\text { Apenas a prefeitura de Curitiba em parceria com o governo do } \\
\text { estado tem um programa integrado de incentivo ao turismo local } \\
\text { verificado pela concessão de desconto nas passagens aos } \\
\text { moradores das cidadestranspassadas pelo trajeto do trem turistico. }\end{array}$ & 2 \\
\hline & $\begin{array}{l}\text { Articulações } \\
\text { entreo poder } \\
\text { públicoe } \\
\text { privado }\end{array}$ & $\begin{array}{l}\text { A cidade apresenta ações não integradas de investimentos ao } \\
\text { fomento do turismo local pela iniciativa privada, porém não há um } \\
\text { convênio ou integração efetiva entre as instâncias público e } \\
\text { privado. }\end{array}$ & 2 \\
\hline & $\begin{array}{l}\text { Produção do } \\
\text { espaço: } \\
\text { prospecçãoe } \\
\text { efetiva }\end{array}$ & $\begin{array}{l}\text { As condições das instalações da estação não atendem a uma } \\
\text { valorização do patrimônio, muito menos a uma prospecção de } \\
\text { espaçospúblicos efetivose comqualidade. }\end{array}$ & 0 \\
\hline & $\begin{array}{l}\text { Contrapartidas } \\
\text { territoriais: } \\
\text { investimentose } \\
\text { infraestrutura }\end{array}$ & $\begin{array}{l}\text { Não há contrapartida terntorial por conta da linha de trem turístico, } \\
\text { não se identificou nenhum tipo de investimento ou infraestrutura } \\
\text { voltada para o município ou bem-estar da população. }\end{array}$ & 1 \\
\hline & Efeitos & Mesmo com a falta de investimento, planejamento ou mesmo de & 1 \\
\hline
\end{tabular}

Fonte: Fernanda D'Agostini, 2017.

Com base na análise dos indicadores e dos critérios de avaliação da influência da ferrovia turística no território, identifica-se na análise SWOT os possíveis cenários (figura 04). 
Figura 04 - Aplicação da análise SWOT à Estrada de Ferro Curitiba - Paranaguá com base nos critérios de avaliação de influência deste equipamento no território discriminadas no item 3.2.

\section{LOCALIZAÇÃO}

\begin{tabular}{c|c}
$\begin{array}{c}\text { Atratividade turística por meio } \\
\text { do patrimônio ferroviário }\end{array}$ & $\begin{array}{c}\text { Conflito de usos: circulação } \\
\text { pedestres, automóveis e trem } \\
\text { por falta de desenho urbano }\end{array}$ \\
PATRIMÔNIO & EQUIPAMENTOS PÚBLICOS \\
\hline $\begin{array}{c}\text { Valoração da educação } \\
\text { patrimonial e ambiental } \\
\text { atrelada ao complexo } \\
\begin{array}{c}\text { ferroviário, assim como, forma } \\
\text { de preservação e }\end{array}\end{array}$ & $\begin{array}{c}\text { A sobrecarga sazonal dos } \\
\text { equipamentos e infraestrutura } \\
\text { pode interferir diretamente no } \\
\text { equilíbrio ambiental, visto que } \\
\text { o município se apresenta em } \\
\text { uma área de mata atlântica. }\end{array}$ \\
edificado.
\end{tabular}

QUALIDADE AMBIENTAL

Autor: Fernanda D'Agostini

Na análise da Ferrovia Turística Curitiba - Morretes verifica-se que os cenários compostos dos cruzamentos: localização versus patrimônio e patrimônio versus qualidade ambiental tem como potencialidades reais para o fomento da atividade turística - base da economia do município de Morretes por meio do fluxo de turistas proporcionado pelas viagens do trem. Devido à proximidade com a cidade de Curitiba, muitos turistas usufruem da cidade e de seus atrativos tendo como meio de acesso à rodovia, em uma viagem de menos de uma hora, o que torna mais atrativa se comparada com a viagem de trem que leva em média três horas para o trajeto de Curitiba a Morretes, esse também é um dos fatores que fazem com que a empresa responsável pela linha turística comercialize o passeio com a volta a Curitiba de vans ou ônibus.

No caso dos cenários compostos dos cruzamentos: localização versus equipamentos públicos e equipamentos públicos versus qualidade ambiental, a ferrovia apresenta uma relação problemática visto que não há nenhuma contrapartida de espaços ou equipamentos para o recebimento dos turistas na cidade, como descrito anteriormente, o que sobrecarrega a infraestrutura da cidade e, principalmente, ocasiona um fluxo de pedestres pelas vias da cidade ocasionando um conflito com os veículos. Observa-se quanto ao desenho das vias, passeios e ferrovia, que não foram adequados à demanda, criando um panorama de risco a todos os usuários, nos cruzamentos indevidos e na falta de equipamentos de segurança junto à linha férrea, como também pela apropriação da orla ferroviária pelos moradores - que além de transitarem cotidianamente pelos trilhos, crianças brincam sobre os mesmos.

Verificou-se que a ferrovia turística tem papel fundamental no desenvolvimento local, no que se refere ao fomento da atividade base da economia, porém não se concretiza quando equalizado nas relações de prospecção de espaços públicos e contrapartidas socioculturais para os moradores.

\section{CONCLUSÃO}

As análises e avaliações desta pesquisa mostraram que a implementação e funcionamento desses equipamentos são truncados pelos fatos políticos e econômicos, além das contrariedades das relações das escalas públicas e privadas, o que induz a uma vulgarização da previsão de espaços públicos nas cidades.

Os estudos apresentados mostram que, em quase totalidade, não existe relação de pertencimento ao lugar, dificultando a formação da memória e identidade, pois as referências temporais tornaram-se intangíveis pela cisão da ferrovia com o território, o que problematizou a materialidade de um processo de valorização do lugar que é um dos pontos 
principais para a promoção do território induzido pelo patrimônio material e imaterial na busca pelo desenvolvimento regional.

Apurou-se que o desenho do território e da paisagem transpassados por essas ferrovias é colocado em segundo plano, o que resulta em uma série de desarticulações e barreiras físicas dentro do tecido urbano induzindo um conflito de uso dos espaços públicos, além do desconforto ou ainda situações de risco aos transeuntes do local. Desta forma, deve-se pensar o desenho do território e da paisagem com a reposição de recursos de infraestrutura e equipamentos públicos que eliminem ou, pelo menos, minimizem os conflitos de usos.

\section{REFERÊNCIAS}

ALLIS, Thiago. Turismo, patrimônio cultural e transporte ferroviário: um estudo sobre ferrovias turísticas no Brasil e na Argentina. Dissertação. (Mestrado em Integração da América Latina). Programa de Pós-graduação em Integração da América Latina - USP, São Paulo, 2006.

ANTT - Agência Nacional de Transportes Terrestres. Legislação. Disponível em: http://www.antt.gov.br/ferrovias/index.html. Acesso em: abril de 2017.

BESSA, Altamiro Sérgio Mol; ALVARES, Lucia Capanema. A Construção do Turismo: megaeventos e outras estratégias de venda das cidades. Belo Horizonte: C/Arte, 2014.

BRASIL. TRIBUNAL DE CONTAS DA UNIÃO. Técnicas de auditoria: indicadores de desempenho e mapa de produtos. Brasília: TCU, Coordenadoria de Fiscalização e Controle, 2000.

. Ministério do Turismo. Plano Nacional de Turismo 2007 - 2010. Brasília: MTur, 2007.

Ministério do Turismo. Programa de Regionalização do Turismo - Roteiros do Brasil. Brasília: MTur, 2009.

. TRIBUNAL DE CONTAS DA UNIÃO. Análise SWOT e Diagrama de Verificação de Risco aplicados em auditoria. Brasília: TCU, Secretaria de Fiscalização e Avaliação de Programas do Governo (Seprog), 2010.

. Ministério do Turismo. Plano Nacional de Turismo 2013 - 2016. Braślia: MTur, 2013.

2013.

Ministério do Turismo. Programa de Regionalização do Turismo: diretrizes. Brasília: MTur,

Ministério do Turismo. Mapa do Turismo Brasileiro. Brasília: MTur, 2013.

COMPANS, Rose. Empreendorismo urbano: entre o discurso e a prática. São Paulo: Editora UNESP, 2005.

GÜELL, José Miguel Fernández. Planificación Estratégica de Ciudades. $2^{a}$ edição. Barcelona: Editorial Gustavo Gili, 2000.

LAW, Christofer M. Urban Tourism: the visitor economy and the growth of large cities. $2^{a}$ edição. Londres: Continuum, 2002.

PEREIRA, Julio Cesar R. Análise de dados qualitativos: estratégias metodológicas para a ciências da saúde, humanas e sociais. 3 ed. São Paulo: Editora da Universidade de São Paulo, 2004.

PONTUAL, Virgínia, LORETTO, Rosane Piccolo (Orgs). Cidade, território e urbanismo: um campo conceitual em construção. Olinda: $\mathrm{CECl}, 2009$. 